\title{
PEDIGREE OF LAMELLAR CATARACT
}

\author{
BY \\ Wajid Ali Khan \\ LONDON
}

My thanks are due to Sir John Parsons and Mr. Holmes Spicer for permission to publish this pedigree.

On March 18, 1925, George G., aged 5 years, was brought to the Royal London Ophthalmic Hospital on account of defective vision and admitted under the care of Sir John Parsons. He was examined under a mydriatic when lamellar cataracts were diagnosed. On further.inquiry it was found that his mother, her two brothers, and her mother had had cataract operations performed in Moorfields Eye Hospital. All the available members of the family were examined under a mydriatic.

Mr. G. (father of the above case) no eye trouble. Examination : corneae clear, irides bright and active. No lens opacities, fundi normal.

John G. (brother), no eye complaint, no lens opacities. Media and fundi normal.

Mary G. (sister), no symptoms, no lens opacities. Media and fundi normal.

The following notes have been taken from the in-patient records :

Thomas P. (maternal uncle), aged 10 years, admitted under care of Mr. Holmes Spicer, April 27, 1900, with a history of failure of sight since measles 18 months ago. Teeth fair and no history of fits.

Examination: R. and L. No mucocele, corneae clear, good anterior chambers. Irides bright, pupils active. Zonular opacities, peripheral red reflex. tion.

April 27, 1900.-Left needling with subsequent curette evacua-

January 23, 1901.-Right needling.

Annie P. (mother), aged 10 years, admitted under care of $\mathrm{Mr}$. Holmes Spicer, July 11, 1902, with history of bad eyesight. Examination : R. and L. No injection, no mucocele, lids healthy, corneae and anterior chambers clear. Reactions normal. Lamellar cataracts.

July 12, 1902.-Left needling with subsequent curette evacuation.

September 19, 1902.-Right needling.

John P. (maternal uncle), aged 6 years, admitted under care of $\mathrm{Mr}$. Holmes Spicer, November 9, 1909, with history of bad eyesight for twelve months. No history of convulsions. Teeth irregular. Examination: R. and L. External parts healthy, corneae bright, pupils active. Lamellar cataracts.

November 19, 1909.-Left needling. 
November 23, 1910.-Right needling.

Annie Maria H. (grandmother), aged 14 years, admitted under care of Mr. Hulke, October 12, 1874. Examination : R. and L. Lamellar cataracts.

October 12, 1874.- - Left needling. Patient did not come back on account of pain.

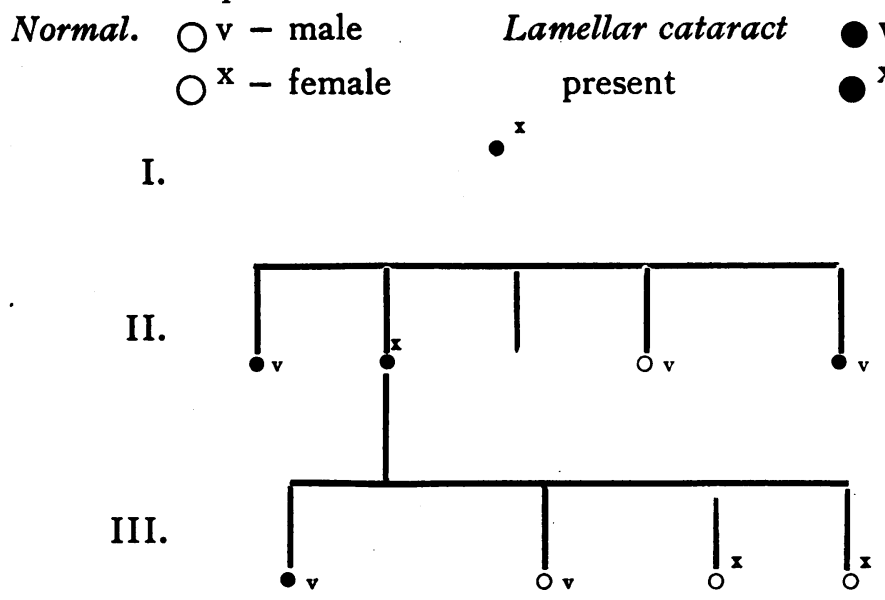

The occurrence of lamellar cataracts in several generations of a family is not very rare, and a number of pedigrees have been worked out ${ }^{(1)}$. These pedigrees do not fulfil all the requirements of the Mendelian theory, and this is not difficult to explain when one takes into consideration the fact that it is impossible to get data of all maternal conceptions; even the number of miscarriages is not easy to ascertain. According to this theory we should have one-quarter or one-half of the offspring affected with the disease in most cases, as shown by the following theoretical results :

$\mathrm{DD}=$ Dominant. $\quad \mathrm{RR}=$ Recessive. $\quad \mathrm{DR}=$ Hybrid.

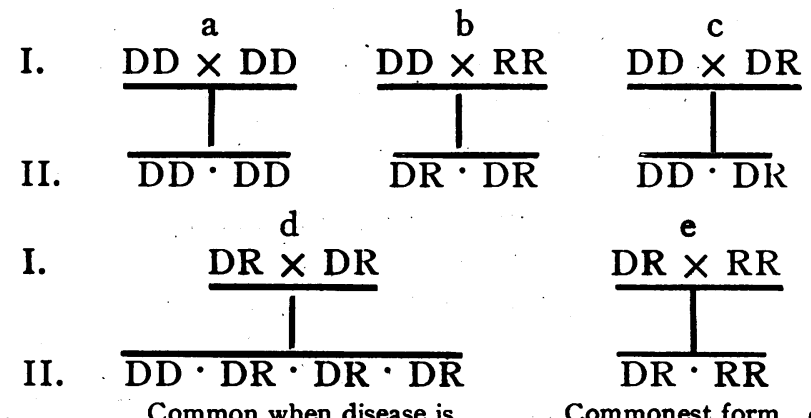

Common when disease is recessive. $\ddagger$ of offspring diseased.

Commonest form, disease either dominant or reces. sive. $\frac{1}{2}$ of offspring in either case diseased. 
There is much in heredity that has to be explained yet, and though the present pedigree does not fit in accurately with the above, it illustrates quite well the influence of heredity in lamellar cataract.

\section{REFERENCES}

1 and 2. Nettleship, E.-Bowman Lecture, Trans. Ophthal. Soc. of the U.K., Vol. XXIX, 1909.

\section{ATYPICAL COLOBOMA OF THE IRIS}

BY

WAJID ALI KHAN

LONDON

THE following case is of interest as it proves the inflammatory origin of at least some cases of atypical colobomata of the iris.

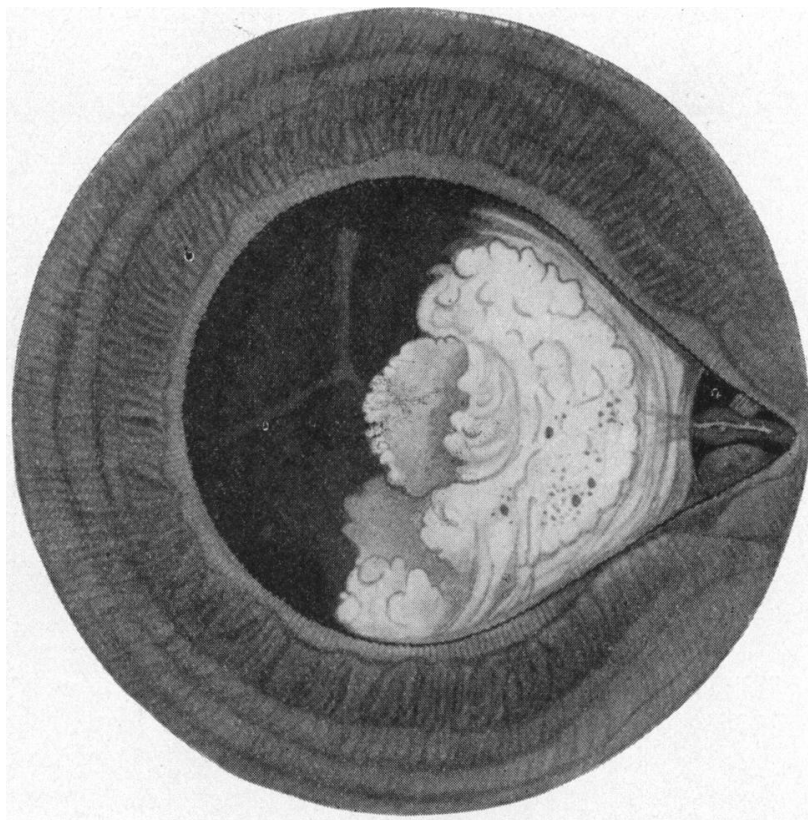

W.F., female, aged 21 years, out-patient, Royal London Ophthalmic Hospital. The sight of the left eye has always been defective; the mother noticed something wrong with the pupil of this eye at birth. There is no history of any injury or inflammation 